Research Article

\title{
Thermal Degradation and Water Uptake of Biodegradable Resin Prepared from Millet Flour and Wheat Gluten Crosslinked with Epoxydized Vegetable Oils
}

\author{
Abdellatif A. Mohamed $(D$, , S. Hussain, M. S. Alamri, M. A. Ibraheem, \\ and Akram A. Abdo Qasem \\ Department of Food Science and Nutrition, King Saud University, Riyadh, Saudi Arabia \\ Correspondence should be addressed to Abdellatif A. Mohamed; abdmohamed@ksu.edu.sa
}

Received 25 March 2019; Revised 28 October 2019; Accepted 7 November 2019; Published 29 November 2019

Academic Editor: Barbara Gawdzik

Copyright ( $\odot 2019$ Abdellatif A. Mohamed et al. This is an open access article distributed under the Creative Commons Attribution License, which permits unrestricted use, distribution, and reproduction in any medium, provided the original work is properly cited.

\begin{abstract}
The degradation temperatures (DTs), heat stability (IPDT), degradation kinetics, and water uptake of epoxy resin were investigated using thermogravimetric analysis. Epoxy resins were prepared by crosslinking epoxydized oils with vital wheat gluten (VG) and millet flour. The reactions included three oils (cottonseed, sesame, and sunflower) and three levels of zinc chloride (ZC) $(1,2$, and $3 \%)$. The apparent activation energy $\left(E_{\mathrm{a}}\right)$ was calculated using the Flynn-Wall-Ozawa method. The DT increased at higher heating rates within the same ZC level of the same oil type. Cottonseed oil exhibited the highest DT. The highest IPDT was $637^{\circ} \mathrm{C}$ of the sunflower oil/millet resin ( $\left.3 \% \mathrm{ZC}\right)$, and the least was the cottonseed/millet $(1 \% \mathrm{ZC})$ at $479^{\circ} \mathrm{C}$. The sesame-millet resin exhibited the highest $E_{\mathrm{a}}(622 \mathrm{KJ} / \mathrm{mol})$ followed by sunflower-gluten $(496 \mathrm{KJ} / \mathrm{mol})$ and sesame-gluten $(454 \mathrm{KJ} / \mathrm{mol})$. The profiles of all resins point to a multistep degradation, but some of the profiles display two dominant kinetic processes, and the remaining resins showed three processes. The variation in crosslinking density between the oils is attributable to the different amounts of oxirane rings which are associated with the double bonds of the fatty acid of the oils. Like other parameters, the water uptake was affected by the ZC content, where most of the resins did not reach water uptake equilibrium. Nonetheless, the $3 \% \mathrm{ZC}$ resin reached equilibrium after 5 days of immersion.
\end{abstract}

\section{Introduction}

Due to the public concern, biodegradable plastics have been developed and used in packaging for environmental protection. This has been instigated by the polluting effect of nondegradable synthetic polymers or petroleum based in ocean and landfills. A number of packing materials, especially food packing, have been developed to meet consumer needs. Despite the advantages of petroleum-based materials such as gas permeability control and resiliency, these materials are not environmentally friendly because of disposal difficulties and the large amounts of heat and exhaust gases generated when burned, thus posing a global environmental pollution threat. As a result of consumer demands and rising petroleum prices, the utilization of environmentally friendly materials became necessary as an alternative to nonrenewable resources originating from agricultural sources.

Epoxy thermoset resins are one of the best reactive industrial materials by virtue of their excellent properties and low cost. They have been widely used in a number of industries including adhesives, automotives, and electronics due to their versatile physicochemical and mechanical properties [1-3]. It is problematic to consider one mechanism of thermal degradation for all epoxy resin because of the different natures of the resin and the chemical nature of the used resin hardener. For instance, di- or triamine acts as a hardener when mixed with epoxy resin chains. The reactive epoxide rings can be opened by the nucleophilic amino groups to crosslink polymer chains together, initiating the polymer hardening process [4-7]. 
Most methodologies used for characterizing the thermal decomposition of materials permit the determination of the activation energy which is the main kinetic parameter. This corresponds to the minimum energy necessary to start a chemical reaction and depends on the state of decomposition, pressure, and temperature. Depending on the number of decomposition steps and the scope of the study, single-step or multiple-step kinetic models were used [8-11]. In the most part, the objectives of using degradation steps were to obtain the best fit between experimental and numerical weight loss curves [12].

The determination of kinetics parameters was centered on developing the least-squares fitting procedure based on DTGA curve measurement at different heating rates [10]. Contingent on the studied material, the decomposition can be highly complex. In addition, it is not reversible and is described by a classical reaction rate following the Arrhenius equation.

Most published methods used for determining degradation kinetic parameters from TGA are derived from three main equations:

$$
\mathrm{DR}=\frac{\mathrm{d} a}{\mathrm{~d} t}=k(T) f(a)
$$

where DR is the degradation rate, $f(a)$ is the reaction model, " $a$ " is the degree of the reaction, $K(T)$ is the temperaturedependent rate constant, " $T$ " is the temperature, and " $t$ " is the time.

The term $K(T)$ is presumed to obey the Arrhenius relationship:

$$
K(T)=A^{-E_{\mathrm{a}} / R T},
$$

where $E_{\mathrm{a}}$ is the activation energy, $A$ is the preexponential factor, and $R$ is the gas constant.

A model-free analysis was proposed by Friedman using thermogravimetric data [10]. It permits to plot the activation energy as a function of the degree of decomposition conversion, which may reveal one or more reaction steps. If the calculated activation energy was constant as a function of decomposition degree, only one reaction occurred and can only be described by the kinetic equation (1). Otherwise, a multistep reaction has to be considered if the activation energy was changing, and the reaction rate of each step can be described. Therefore, the kinetic model could include independent reactions, successive reactions, and competitive reactions or a mixture of all reaction types [13-15].

One of the most important characteristics of resins is the water uptake. Becker et al. reported that water uptake of neat polymers is higher than the composite of the same polymer blended with nanoclays [16]. The decomposition process of organic materials can be divided into three stages: desorption of water and other low-molecular-weight organic species (below $180^{\circ} \mathrm{C}$ ), followed by the decomposition of organic substances $\left(200-500^{\circ} \mathrm{C}\right)$, where other compounds degrade between 500 and $1000^{\circ} \mathrm{C}$ [17]. Water uptake of epoxy resin has been widely studied because of the effect of water on the neat resin performance and its composites. Epoxy resin water uptake is often related to the free volume of the resin. Other researchers found a strong correlation between the whole volume of the resin and the water uptake [18]. Tscharkhtchi et al. reported that water uptake causes no change in the volume (no swelling) of the material because water dissolves in the polar regions of the resin [19].

The work presented here investigated the thermal degradation of a biodegradable epoxy resin prepared from millet flour and wheat gluten crosslinked with different epoxydized vegetable oils. The degradation kinetics, heat stability, and water uptake properties were examined.

\section{Materials and Methods}

2.1. Materials. ASVOC sunflower oil, sesame, and cottonseed oils (Arab Sudanese Vegetable Oil Company, Khartoum North, Sudan) were purchased from a local supermarket. Yellow millet flour (MF) grown in Jazan (Saudi Arabia) was purchased from the local market, and vital wheat gluten (VG) was obtained from Midwest Grain Products (Pekin, IL).

2.2. Development of Epoxydized Oils. Oil epoxydization was performed by reacting oil with hydrogen peroxide in the presence of formic acid. The oil of interest (about $280 \mathrm{~g}$ ) was placed in a flask with a heating jacket. On the top of the flask, a mechanical stirrer was placed. The initial temperature was $40^{\circ} \mathrm{C}$ [20] increased to $70^{\circ} \mathrm{C}$ after adding $25 \mathrm{ml}$ formic acid and $200 \mathrm{ml}$ of $50 \%$ peroxide solution with constant stirring. The reaction time varied according to oil type and protein source. The product was washed with saturated ethyl acetate $(\mathrm{pH} 7.5)$ and $\mathrm{NaCl}$ and dried in a vacuum oven at $60^{\circ} \mathrm{C}$.

2.3. Analysis of Epoxydized Oils. The yield of the epoxydization reaction was tested by the Fourier Transform Infrared (FTIR) Attenuated Total Reflection (ATR) method (Bruker Alpha-Eco ATR-FTIR, Bruker Optics Inc., Ettlingen, Germany). The epoxy ring bonds, C-O-C stretching, were detected at $824-842 \mathrm{~cm}^{-1}$ using the FTIR [20]. The end of the reaction was determined by monitoring the size of the oxirane peak as well as the amide I and amide II bands. The reaction ends when the oxirane peaks fade away.

2.4. Development of Epoxy Resin. The curing process of the epoxy resin reaction was carried out by adding epoxydized oil $(50 \mathrm{~g})$ in a glass reactor at $70^{\circ} \mathrm{C}$, followed by 1,2 , or $3 \%$ of zinc chloride $\left(\mathrm{ZnCl}_{2}\right)$ and little nitrogen purge. The vital gluten $(20 \mathrm{~g})$ was added slowly at $500 \mathrm{rpm}$ and increased to $750 \mathrm{rpm}$ for the duration of the reaction. The thickness of the product texture and the disappearance of the $\mathrm{C}-\mathrm{O}-\mathrm{C}$ bonds and reduction in amide I and II bands were used as indicators of the end of the reaction. The most obvious sign of the end of the reaction is the rise in the product thickness, where the material turns into a thick mass that prevented the stirrer from turning. This is, in addition, to the disappearance of the $\mathrm{C}-\mathrm{O}-\mathrm{C}$ band at $845-824 \mathrm{~cm}^{-1}$, as mentioned earlier, and the reduction in amide I at $1375 \mathrm{~cm}^{-1}$ and II at $1236 \mathrm{~cm}^{-1}$ on the IR spectrum. 
2.5. Thermal Stability. The thermal stability of polymers can be predicted according to the integral procedure decomposition temperature (IPDT) suggested by Doyle in 1961 [21]. The IPDT has been correlated with the volatile parts of polymeric materials and used for assessing the intrinsic thermal stability of polymers.

IPDT was calculated from IPDT $\left({ }^{\circ} \mathrm{C}\right)=A^{*} K^{*}(\mathrm{Tf}-\mathrm{Ti})$ $+\mathrm{Ti}:$

$$
\begin{aligned}
A^{*} & =\frac{S_{1}+S_{2}}{S_{1}+S_{2}+S_{3}}, \\
K^{*} & =\frac{S_{1}+S_{2}}{S_{1}},
\end{aligned}
$$

where $A^{*}$ is the area ratio of the experimental TGA curve defined by the total thermogram area, as shown in Figure 1 . $\mathrm{Ti}$ is the initial temperature, and Tf is the final experimental temperature.

2.6. Thermal Degradation Kinetics. Thermogravimetric analysis (TGA) was performed using a 2050 DTGA (TA Instruments, New Castle, DE). Samples $(10 \mathrm{mg})$ were heated at 20,30 , and $40^{\circ} \mathrm{C} / \mathrm{min}$. The furnace was purged with nitrogen for the duration of the test $(60 \mathrm{ml} / \mathrm{min})$. The TGA data were plotted as temperature versus weight $\%$ or derivative weight $\%$, from which onset, final, and peak decomposition temperatures were obtained. The activation energy was determined at all heating rates, and the percentage conversion per minute was reported. After analysis, kinetics data were obtained using the TA Specialty Library software, with reported activation energies at 50\% conversion.

By applying the multiple heating rate method, TGA can be used to calculate the degradation activation energy according to Flynn-Wall-Ozawa equation (3):

$$
\log \beta=0.457\left(\frac{-E_{\mathrm{a}}}{R T}\right)+\left\{\log \left(\frac{A E_{\mathrm{a}}}{R}\right)-\log F(a)-2.315\right\},
$$

where $\beta$ is the heating rate, $T$ is the absolute temperature, $R$ is the gas constant, $a$ is the conversion, $E_{\mathrm{a}}$ is the activation energy, and $A$ is the preexponential factor. Therefore, the activation energy $E_{\mathrm{a}}$ is obtained from the slope of the right $\log \beta$ vs. $1 / T$ corresponding to certain conversion $\left[E_{\mathrm{a}}=-R *\right.$ slope $\left./(0.457)\right]$.

2.7. Water Uptake. Specimens of each material with dimensions $90 \times 90 \times 140 \mathrm{~mm}$ were placed in beakers filled with distilled water, and the temperature of the water bath was set at $80 \pm 1^{\circ} \mathrm{C}$. After definite time interims, samples were removed from the beaker, dried with paper towel, and weighed on analytical scale. The results have been plotted in terms of percentage of mass uptake $M_{i}$ versus time $t$, according to the following equation:

$$
M_{i}(t)=\frac{M(t)-M(0)}{M(0)},
$$

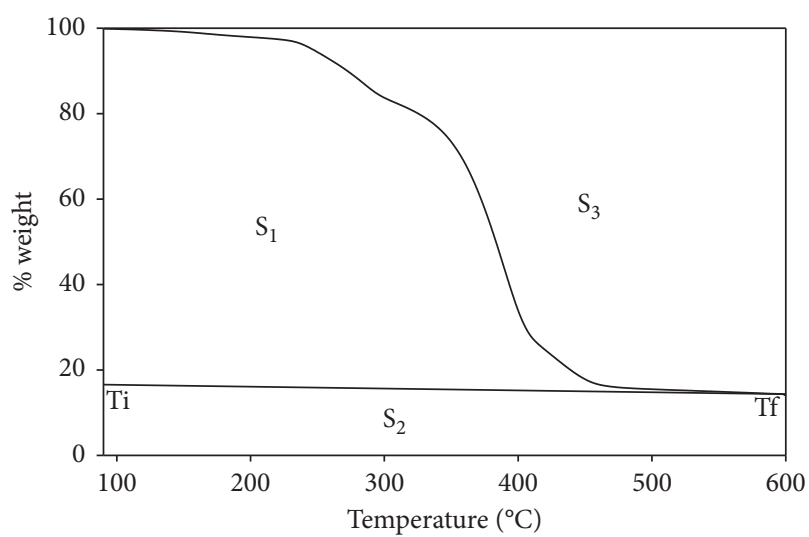

Figure 1: Epoxydized cottonseed oil/gluten and 2\% zinc chloride heated at $20^{\circ} \mathrm{C} / \mathrm{min}$ : TGA representation of $S_{1}, S_{2}$, and $S_{3}$.

where $M(t)$ is the weight at the time $t$ and $M(0)$ is the initial weight before insertion in water.

\section{Results and Discussion}

The development of the oxirane ring during oil epoxydization was monitored by FTIR. Figure 2 shows how the oxirane ring was detected using FTIR around $824-842 \mathrm{~cm}^{-1}$, where the figure illustrates the difference between the oils with respect to the peak size and location. Sunflower oil had more oxirane rings compared to the sesame and the cottonseed by virtue of the difference in fatty acid composition, in addition to the higher amide I and II. Cottonseed oil contained the least amount of oxirane rings and amid I bands (profile is not shown). In addition, sesame oil had the oxirane ring and amid II in between the other two oils. Figure 3 shows representative TGA degradation thermograms of epoxy resin of millet flour crosslinked with all three oils with $3 \%$ zinc chloride (ZC) heated at $20^{\circ} \mathrm{C} / \mathrm{min}$ from $30^{\circ} \mathrm{C}$ to $600^{\circ} \mathrm{C}$ in nitrogen environment.

\subsection{Onset and Peak Temperature of Degradation.} Thermogravimetric (TG) curves were analyzed in terms of the decomposition onset temperature $(\mathrm{ON})$ and the temperature at the peak of degradation (DPT). The ON of degradation is usually taken after $5 \%$ of the material is degraded. The tested resins exhibited two types of profile at all heating rates and percent $\mathrm{ZC}$, where resins based on vital gluten (VG) exhibited one main peak and two minor shoulders at the beginning and the end of the degradation profile (Figure 4), whereas the resins based on millet flour (MF) exhibited two distinct peaks (Figure 5).

In general, the ON varied according to oil type which is due to the difference in the amount of oxirane ring. The ON increased at higher heating rates within the same ZC level regardless of oil type; however, within the same heating rate and at higher ZC, it decreased (Tables 1 and 2). The data were compared by looking at the $\mathrm{ON}$ at the same heating rate and $\mathrm{ZC}$ level for different oil types. With respect to ON, oils rank as sunflower oil $>$ cottonseed $>$ sesame (Tables 1 and 2). Therefore, regardless of the oil type, the ON gluten or millet- 


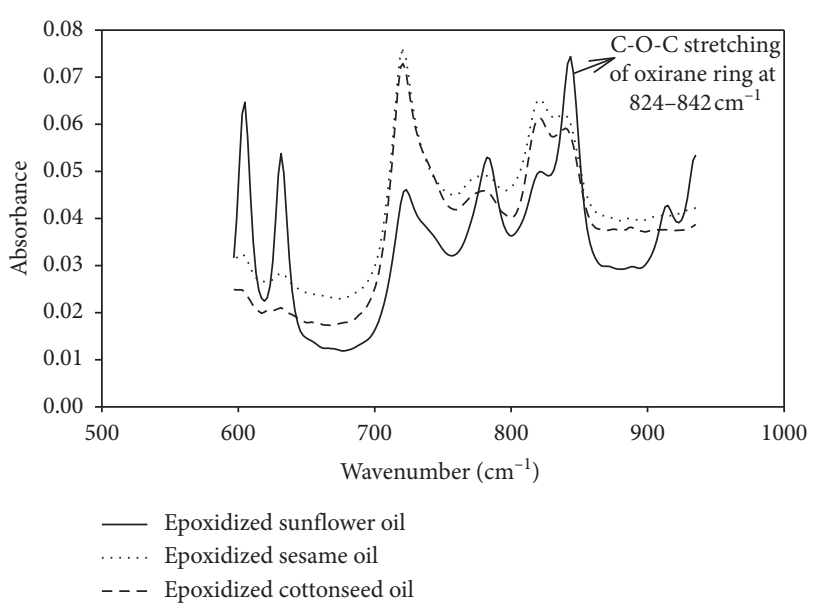

FIgURE 2: FTIR spectra of epoxydized oils.

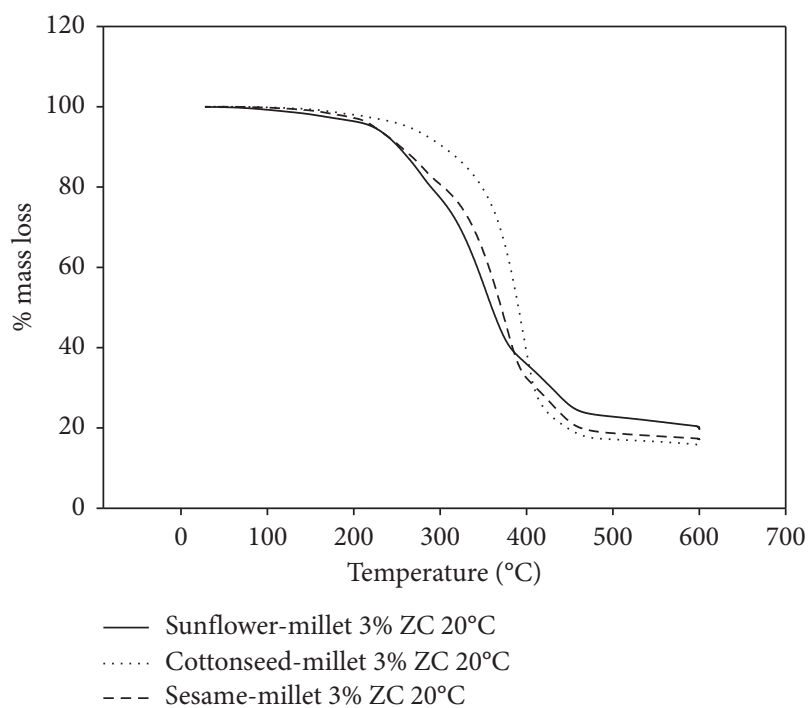

FIGURE 3: Epoxy resin TGA thermograms of sunflower, cottonseed, and sesame oil blended with millet flower and 3\% zinc chloride.

based resins were affected in the same way. The DPT for both resins increased at a higher heating rate within the same $\mathrm{ZC}$ level except for millet resin at 3\% ZC of cottonseed and sunflower (Tables 1 and 2). The ranking of the oils pertaining to the DPT was cottonseed $>$ sunflower $>$ sesame. The DPT of the gluten resin increased at higher ZC except for sesame oil at 3\% ZC. Therefore, samples with lower DPT could be described as low in crosslinking density and high free volume by virtue of low ZC content $[22,23]$. Sesame oil resin exhibited the lowest $\mathrm{ON}$ and DPT compared to the other oils which could be attributed to the presence of excess volatiles or low-molecular-weight fragment generated during crosslinking. The differences in crosslinking density between the oils are attributed to the different amounts of oxirane rings which are associated with the double bonds of the fatty acid of the designated oils. At temperatures far above the glass transition of a low DPT resin, it becomes more expansible and creates more gaps between the molecules of the

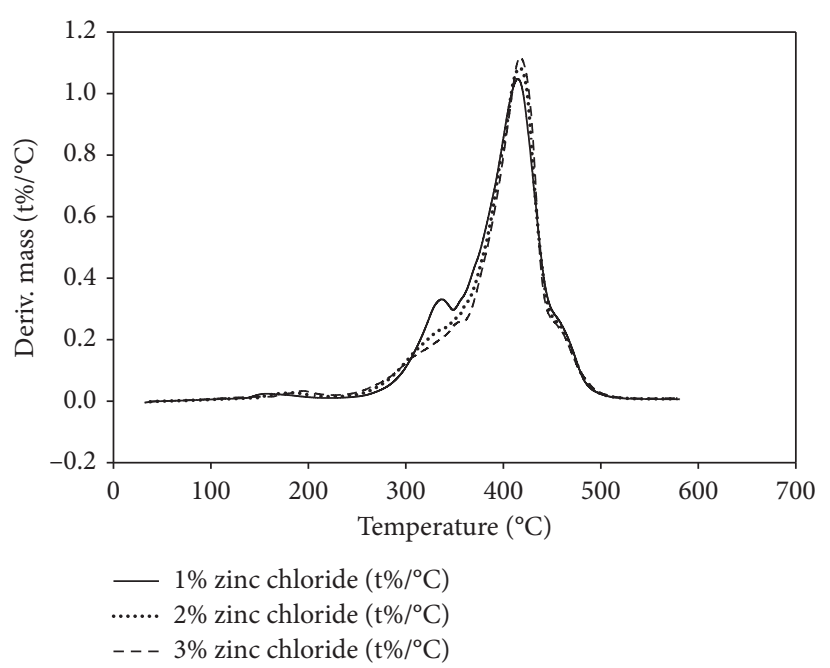

FIgURE 4: TGA profiles for epoxydized sunflower oil crosslinked with gluten and 1,2 , and $3 \%$ zinc chloride heated at $20^{\circ} \mathrm{C} / \mathrm{min}$.

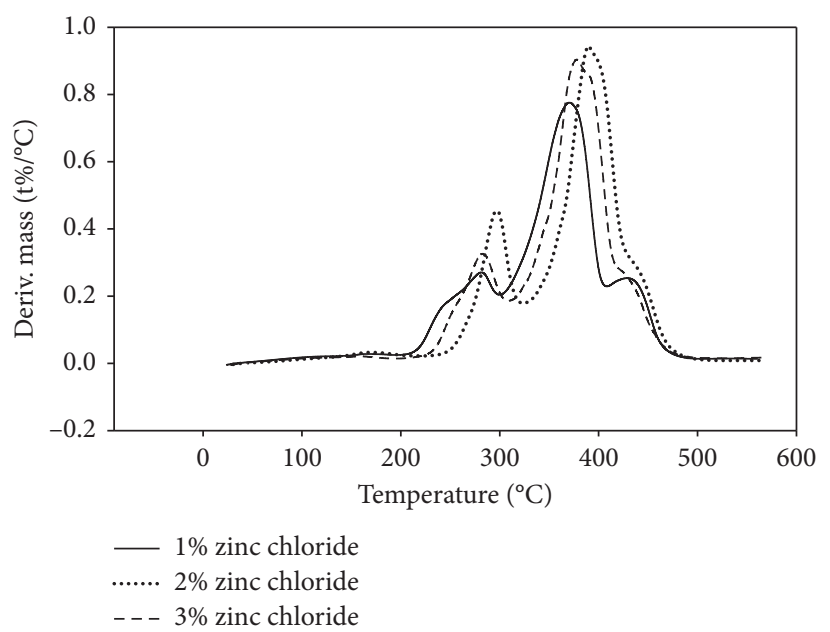

FIgURE 5: TGA profiles for epoxydized sunflower oil crosslinked with millet and 1,2 , and $3 \%$ zinc chloride heated at $20^{\circ} \mathrm{C} / \mathrm{min}$.

formed network amid crosslinking [24]. These gaps permit for the diffusion and evaporation of the volatile materials or the degradation of the low-molecular-weight compounds at the first phase of decomposition. The TGA degradation thermograms in Figure 6(a) show the behavior of glutenbased resin at different ZC levels, whereas in Figure 6(b), the profiles of the resins based on different types of oil at the same heating rate and $\mathrm{ZC}$ content are illustrated. The profiles demonstrated how the addition of $3 \% \mathrm{ZC}$ can delay the degradation of the cottonseed/gluten resin compared to the $1 \%$ and $2 \%$, while the $2 \%$ exhibited the lowest $\mathrm{ON}$ (Figure $6(\mathrm{a})$ ). The $\mathrm{ON}$ of the $2 \%$ zinc chloride resin is expected to be in between the $1 \%$ and the $3 \%$, but it was lower than the $1 \% \mathrm{ZC}$. The behavior of the $2 \% \mathrm{ZC}$ could be attributed to the presence of more space between the molecules taking part in creating the resin. This space allows for lower DPT after the resin reaches glass transition. This behavior was observed for the DPT discussed above. 
TABle 1: Degradation onset and the temperature at the maximum degradation rate of gluten-based epoxy resin.

\begin{tabular}{|c|c|c|c|c|c|}
\hline Oil type & $\%$ zinc & Heating rate $\left({ }^{\circ} \mathrm{C} / \mathrm{min}\right)$ & Onset temperature & Temperature at maximum degradation rate & $\%$ residue \\
\hline \multirow{9}{*}{ Cottonseed } & \multirow{3}{*}{1} & 20 & 283 & 398 & 11.6 \\
\hline & & 30 & 296 & 413 & 11.7 \\
\hline & & 40 & 300 & 420 & 11.8 \\
\hline & \multirow{3}{*}{2} & 20 & 274 & 399 & 14.3 \\
\hline & & 30 & 286 & 408 & 12.9 \\
\hline & & 40 & 296 & 420 & 12.6 \\
\hline & \multirow{3}{*}{3} & 20 & 254 & 396 & 15.5 \\
\hline & & 30 & 275 & 403 & 15.4 \\
\hline & & 40 & 301 & 410 & 15.1 \\
\hline \multirow{9}{*}{ Sesame } & \multirow{3}{*}{1} & 20 & 286 & 398 & 10.8 \\
\hline & & 30 & 294 & 403 & 11.1 \\
\hline & & 40 & 299 & 412 & 10.8 \\
\hline & \multirow{3}{*}{2} & 20 & 234 & 387 & 16.8 \\
\hline & & 30 & 288 & 408 & 12.7 \\
\hline & & 40 & 293 & 414 & 12.5 \\
\hline & \multirow{3}{*}{3} & 20 & 264 & 403 & 16.6 \\
\hline & & 30 & 274 & 399 & 15.7 \\
\hline & & 40 & 285 & 412 & 14.9 \\
\hline \multirow{9}{*}{ Sunflower } & \multirow{3}{*}{1} & 20 & 279 & 391 & 11.6 \\
\hline & & 30 & 295 & 407 & 12.6 \\
\hline & & 40 & 304 & 415 & 11.6 \\
\hline & \multirow{3}{*}{2} & 20 & 280 & 397 & 14.2 \\
\hline & & 30 & 291 & 401 & 13.5 \\
\hline & & 40 & 295 & 417 & 12.4 \\
\hline & \multirow{3}{*}{3} & 20 & 222 & 354 & 20.3 \\
\hline & & 30 & 274 & 399 & 15.8 \\
\hline & & 40 & 287 & 417 & 15.1 \\
\hline
\end{tabular}

TABle 2: Degradation onset and temperature at the maximum degradation rate of millet flour-based epoxy resin.

\begin{tabular}{|c|c|c|c|c|c|}
\hline Oil type & $\%$ zinc & Heating rate $\left({ }^{\circ} \mathrm{C} / \mathrm{min}\right)$ & Onset temperature & Temperature at maximum degradation rate & $\%$ residue \\
\hline \multirow{9}{*}{ Cottonseed } & \multirow{3}{*}{1} & 20 & 277 & 399 & 11.3 \\
\hline & & 30 & 286 & 412 & 11.2 \\
\hline & & 40 & 289 & 417 & 10.3 \\
\hline & \multirow{3}{*}{2} & 20 & 242 & 380 & 14.2 \\
\hline & & 30 & 245 & 393 & 14.0 \\
\hline & & 40 & 258 & 401 & 13.5 \\
\hline & \multirow{3}{*}{3} & 20 & 225 & 373 & 18.5 \\
\hline & & 30 & 241 & 387 & 15.8 \\
\hline & & 40 & 239 & 379 & 16.8 \\
\hline \multirow{9}{*}{ Sesame } & \multirow{3}{*}{1} & 20 & 286 & 395 & 11.8 \\
\hline & & 30 & 294 & 411 & 11.4 \\
\hline & & 40 & 284 & 412 & 11.9 \\
\hline & \multirow{3}{*}{2} & 20 & 237 & 385 & 9.9 \\
\hline & & 30 & 242 & 389 & 15.9 \\
\hline & & 40 & 250 & 395 & 12.3 \\
\hline & \multirow{3}{*}{3} & 20 & 221 & 375 & 17.3 \\
\hline & & 30 & 227 & 380 & 16.9 \\
\hline & & 40 & 237 & 394 & 16.5 \\
\hline \multirow{9}{*}{ Sunflower } & \multirow{3}{*}{1} & 20 & 263 & 390 & 12.7 \\
\hline & & 30 & 279 & 411 & 11.3 \\
\hline & & 40 & 285 & 416 & 10.4 \\
\hline & \multirow{3}{*}{2} & 20 & 252 & 377 & 12.2 \\
\hline & & 30 & 274 & 408 & 12.3 \\
\hline & & 40 & 270 & 401 & 12.7 \\
\hline & \multirow{3}{*}{3} & 20 & 234 & 370 & 24.4 \\
\hline & & 30 & 213 & 345 & 17.4 \\
\hline & & 40 & 247 & 385 & 15.3 \\
\hline
\end{tabular}




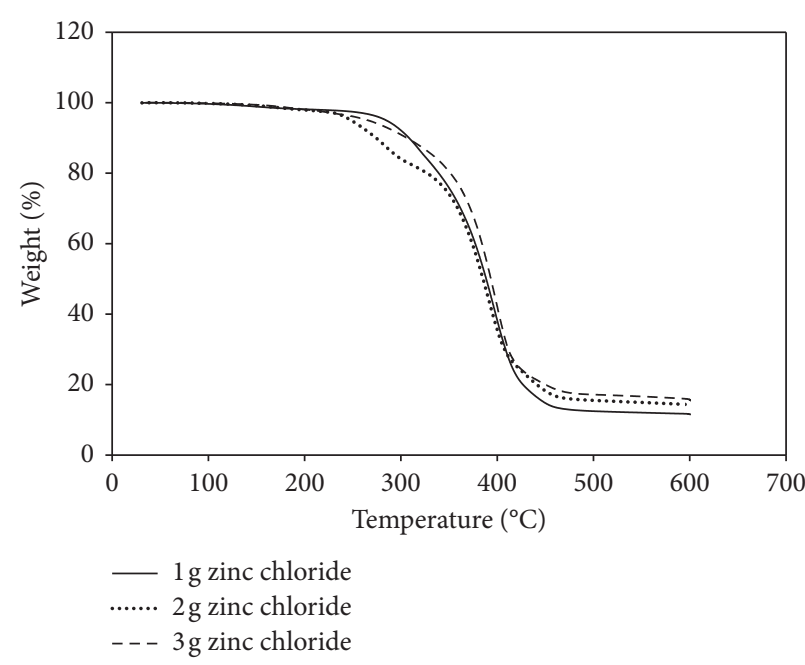

(a)

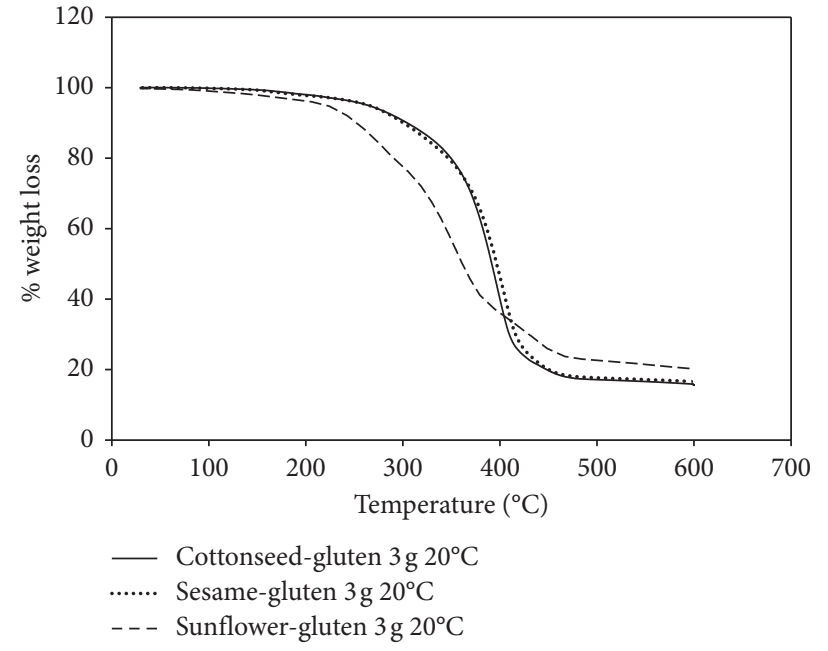

(b)

Figure 6: (a) TGA profile of epoxydized cottonseed oil crosslinked with vital gluten at 1, 2, and 3\% zinc chloride heated at $20^{\circ} \mathrm{C} / \mathrm{min}$; (b) epoxy resin TGA thermograms of sunflower, cottonseed, and sesame oil crosslinked with gluten at $3 \%$ zinc chloride and heated at $20^{\circ} \mathrm{C} / \mathrm{min}$.

However, when comparing the three oils at the same heating rate and ZC content, cottonseed and sesame oils exhibited similar profiles, whereas the ON of sunflower oil was much lower and the profile appeared to have more than one degradation step, as shown in Figure 6(b).

At the end of thermal degradation, the residue of sunflower oil in Figure 6(b) was much higher than the other oils indicating more heat resistant. This behavior is well illustrated by the IPDT values of sunflower oil (to be presented later in the discussion). In general, the residue of some of the tested samples was affected by the heating rate and the ZC content, as shown in Tables 1 and 2. Resins based on gluten exhibited lower residue at higher heating rates with some exceptions especially at $1 \% \mathrm{ZC}$ (Table 1 ). Compared to the other ZC levels, the $3 \%$ zinc chloride seems to maintain lower residue at higher heating rates. All three oils of the millet-based resin exhibited lower residue at a higher heating rate and 3\% zinc chloride. Unlike cottonseed-millet resins, sesame and sunflower oils exhibited mixed residue content (Table 2). The gluten and millet resins exhibited different residues and responded differently to heating rates. Regarding the highest percent residue, resins can be ranked as $3 \%$ ZC sunflower-millet $>3 \%$ sunflower-gluten $>3 \%$ cottonseed-millet. So, millet resins are more heat resistant than vital gluten resins. This variation in residue content could be attributed to the formation of a layer on the surface of the resin during heating that acted as the heat barrier which prevented further degradation and thus higher residue [24]. Certainly, the presence of carbohydrates in the millet flour could be the reason for the heat resistance.

3.2. Thermal Stability. Schematic representation of $S_{1}, S_{2}$, and $S_{3}$ is illustrated in Figure 7 for calculating $A^{*}$ and $K^{*}$. The integral procedure decomposition temperature (IPDT) of the resin depended on the type of oil as well as the level of zinc chloride. Regardless of the oil type, resins exhibited

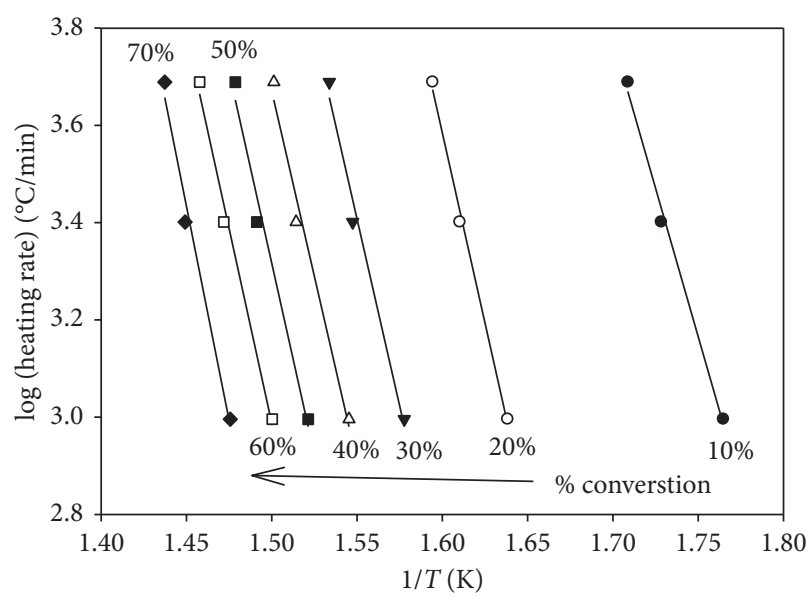

Figure 7: Log beta vs. 1/T plots of TGA kinetics analysis of cottonseed oil + gluten $+3 \mathrm{~g}$ zinc chloride (data analyzed at $50 \%$ conversion).

higher thermal stability at a higher zinc chloride content (Tables 3 and 4). With respect to ZC content, IPDT values can be ranked as $3 \%>2 \%>1 \%$, whereas sunflower-millet resin exhibited the highest IPDT followed by sunflowergluten resin. This was apparent in the size of $S_{1}$ of the resin. Nonetheless, vital gluten resins exhibited overall higher IPDT than millet resin (Tables 3 and 4). The most heatresistant resin was the sunflower oil/millet resin with $3 \%$ zinc chloride, whereas the least was the cottonseed/millet at $1 \%$ zinc chloride. This difference was also observed for the degradation ON and the heat resistant, where sunflower oil ranked the highest and ranked second with respect to DPT. The zinc chloride content which played the role of opening the oxirane ring amid the crosslinking reaction appeared to be the cause of the high IPDT value as shown in Tables 3 and 4. In these tables, linear increase in IPDT was observed as a function of the zinc chloride content. In Tables 3 and 4, the 
TABle 3: $A^{*}, K^{*}$, and IPDT values of gluten-based epoxy resin.

\begin{tabular}{|c|c|c|c|c|c|}
\hline Oil type & $\%$ zinc & Heating rate $\left({ }^{\circ} \mathrm{C} / \mathrm{min}\right)$ & $A^{*}$ & $K^{*}$ & IPDT $\left({ }^{\circ} \mathrm{C}\right)$ \\
\hline \multirow{9}{*}{ Cottonseed } & \multirow{3}{*}{1} & 20 & 0.654749 & 1.213251 & 482.79 \\
\hline & & 30 & 0.684861 & 1.245895 & 516.36 \\
\hline & & 40 & 0.689713 & 1.212412 & 506.64 \\
\hline & \multirow{3}{*}{2} & 20 & 0.644496 & 1.318406 & 514.33 \\
\hline & & 30 & 0.683687 & 1.244571 & 515.01 \\
\hline & & 40 & 0.698348 & 1.231833 & 520.34 \\
\hline & \multirow{3}{*}{3} & 20 & 0.680060 & 1.322292 & 542.56 \\
\hline & & 30 & 0.682641 & 1.289022 & 531.56 \\
\hline & & 40 & 0.696953 & 1.284269 & 540.19 \\
\hline \multirow{9}{*}{ Sesame } & \multirow{3}{*}{1} & 20 & 0.707992 & 1.176271 & 504.69 \\
\hline & & 30 & 0.671376 & 1.193672 & 486.79 \\
\hline & & 40 & 0.731167 & 1.179574 & 521.60 \\
\hline & \multirow{3}{*}{2} & 20 & 0.655063 & 1.175619 & 468.95 \\
\hline & & 30 & 0.720581 & 1.204996 & 524.92 \\
\hline & & 40 & 0.726715 & 1.199092 & 526.69 \\
\hline & \multirow{3}{*}{3} & 20 & 0.680620 & 1.324101 & 543.68 \\
\hline & & 30 & 0.674353 & 1.28029 & 522.11 \\
\hline & & 40 & 0.729038 & 1.248338 & 548.74 \\
\hline \multirow{9}{*}{ Sunflower } & \multirow{3}{*}{1} & 20 & 0.653079 & 1.235162 & 489.79 \\
\hline & & 30 & 0.683507 & 1.213491 & 502.77 \\
\hline & & 40 & 0.651776 & 1.227678 & 486.09 \\
\hline & \multirow{3}{*}{2} & 20 & 0.706609 & 1.234871 & 527.36 \\
\hline & & 30 & 0.673596 & 1.223433 & 499.71 \\
\hline & & 40 & 0.701396 & 1.242226 & 526.63 \\
\hline & \multirow{3}{*}{3} & 20 & 0.694171 & 1.410607 & 588.14 \\
\hline & & 30 & 0.680268 & 1.281941 & 527.07 \\
\hline & & 40 & 0.705344 & 1.289541 & 548.45 \\
\hline
\end{tabular}

$A^{*}=\left(S_{1}+S_{2}\right) /\left(S_{1}+S_{2}+S_{3}\right) ;$ IPDT = integral procedure decomposition temperature; $K^{*}=\left(S_{1}+S_{2}\right) / S_{1}$.

TABLe 4: $A^{*}, K^{*}$, and IPDT values of millet flour-based epoxy resin.

\begin{tabular}{|c|c|c|c|c|c|}
\hline Oil type & $\%$ zinc & Heating rate $\left({ }^{\circ} \mathrm{C} / \mathrm{min}\right)$ & $A^{*}$ & $K^{*}$ & IPDT $\left({ }^{\circ} \mathrm{C}\right)$ \\
\hline \multirow{9}{*}{ Cottonseed } & \multirow{3}{*}{1} & 20 & 0.655991 & 1.201462 & 479.24 \\
\hline & & 30 & 0.668282 & 1.202189 & 487.93 \\
\hline & & 40 & 0.716270 & 1.173192 & 508.98 \\
\hline & \multirow{3}{*}{2} & 20 & 0.690571 & 1.254832 & 523.93 \\
\hline & & 30 & 0.658494 & 1.274895 & 508.52 \\
\hline & & 40 & 0.666451 & 1.255766 & 507.03 \\
\hline & \multirow{3}{*}{3} & 20 & 0.646312 & 1.38775 & 541.24 \\
\hline & & 30 & 0.661318 & 1.322923 & 528.67 \\
\hline & & 40 & 0.662946 & 1.348469 & 539.55 \\
\hline \multirow{9}{*}{ Sesame } & \multirow{3}{*}{1} & 20 & 0.651882 & 1.227957 & 486.27 \\
\hline & & 30 & 0.673091 & 1.207676 & 493.34 \\
\hline & & 40 & 0.691801 & 1.205409 & 505.32 \\
\hline & \multirow{3}{*}{2} & 20 & 0.699793 & 1.165729 & 494.98 \\
\hline & & 30 & 0.651967 & 1.275804 & 504.11 \\
\hline & & 40 & 0.659277 & 1.246865 & 498.55 \\
\hline & \multirow{3}{*}{3} & 20 & 0.695903 & 1.328026 & 556.78 \\
\hline & & 30 & 0.656102 & 1.341019 & 531.51 \\
\hline & & 40 & 0.707630 & 1.313633 & 559.85 \\
\hline \multirow{9}{*}{ Sunflower } & \multirow{3}{*}{1} & 20 & 0.646297 & 1.246318 & 489.13 \\
\hline & & 30 & 0.685042 & 1.199011 & 498.18 \\
\hline & & 40 & 0.677150 & 1.186282 & 487.87 \\
\hline & \multirow{3}{*}{2} & 20 & 0.688991 & 1.224502 & 510.89 \\
\hline & & 30 & 0.677071 & 1.215564 & 499.12 \\
\hline & & 40 & 0.673510 & 1.235181 & 504.19 \\
\hline & \multirow{3}{*}{3} & 20 & 0.644288 & 1.312685 & 512.07 \\
\hline & & 30 & 0.680672 & 1.565124 & 637.24 \\
\hline & & 40 & 0.682174 & 1.344727 & 552.88 \\
\hline
\end{tabular}




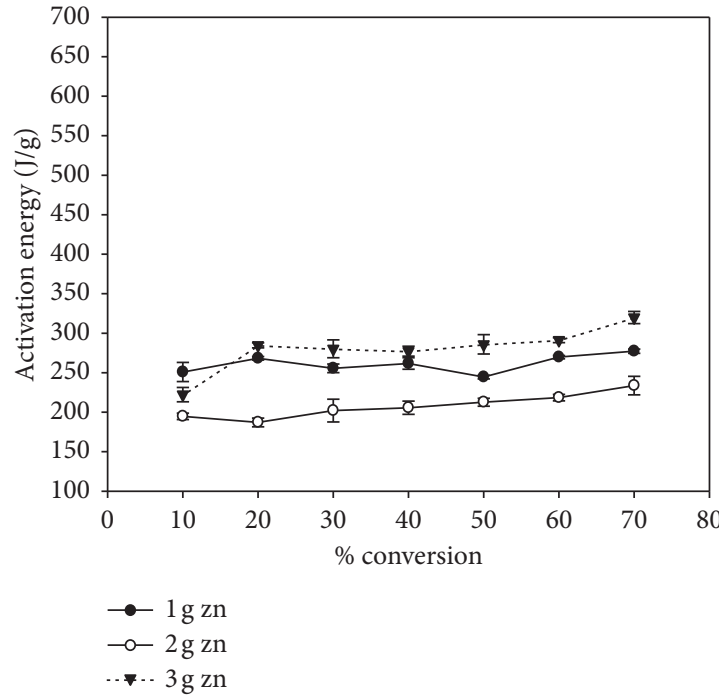

(a)

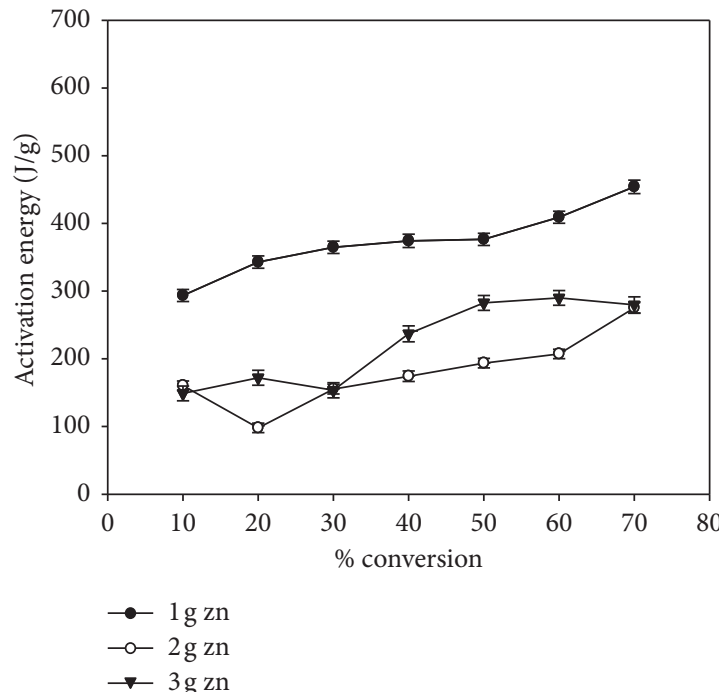

(c)

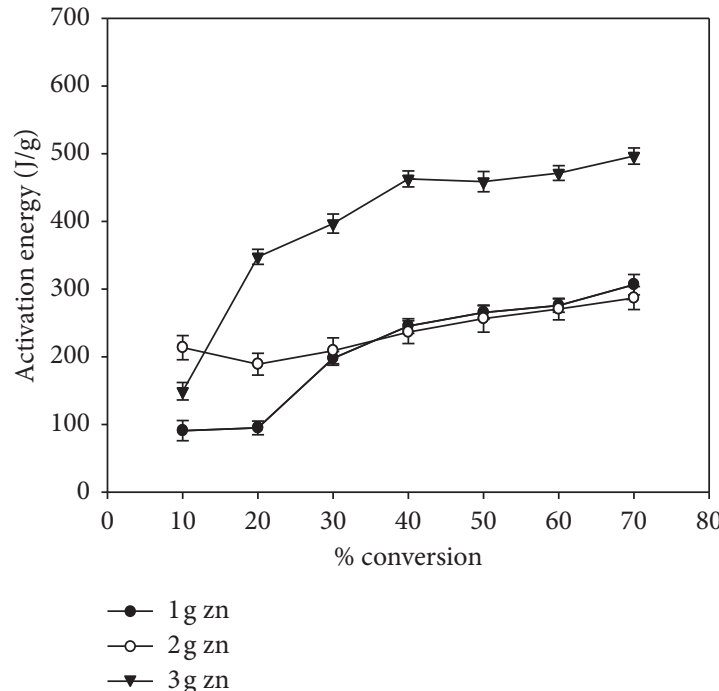

(e)

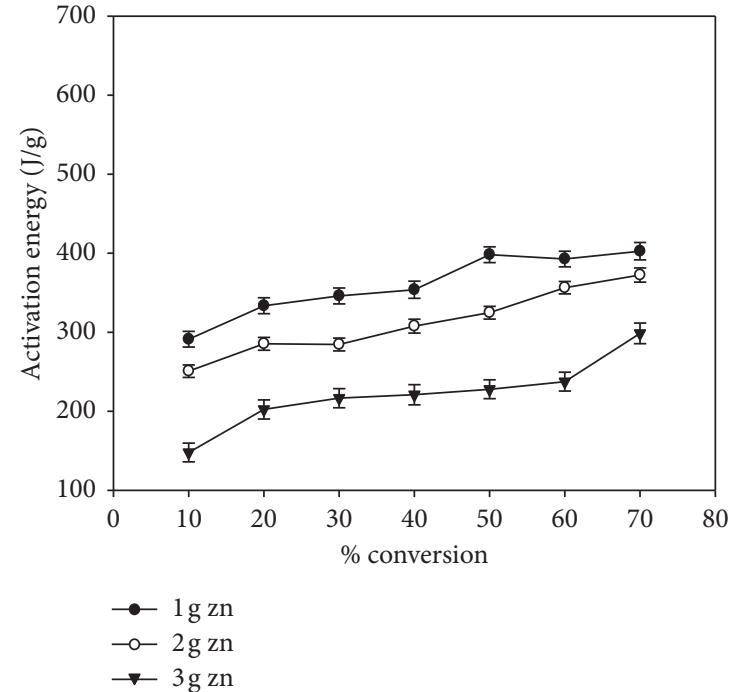

(b)

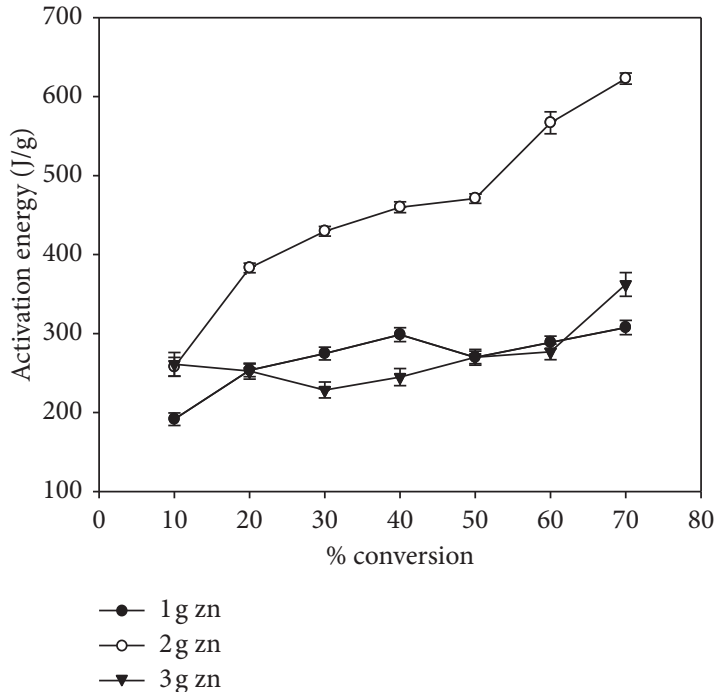

(d)

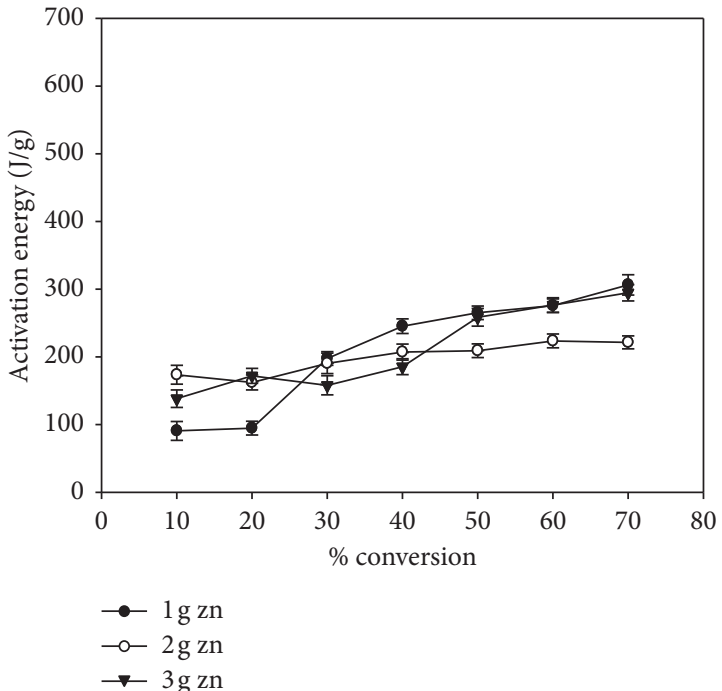

(f)

FIGURE 8: Activation energy of epoxy resin of cottonseed, sesame, and sunflower oils as a function of $\%$ conversion at three zinc chloride (zn) levels: (a) cottonseed oil + gluten; (b) cottonseed oil + millet flour; (c) sesame oil + gluten; (d) sesame oil + millet; (e) sunflower oil + gluten; (f) sunflower oil + millet flour. 

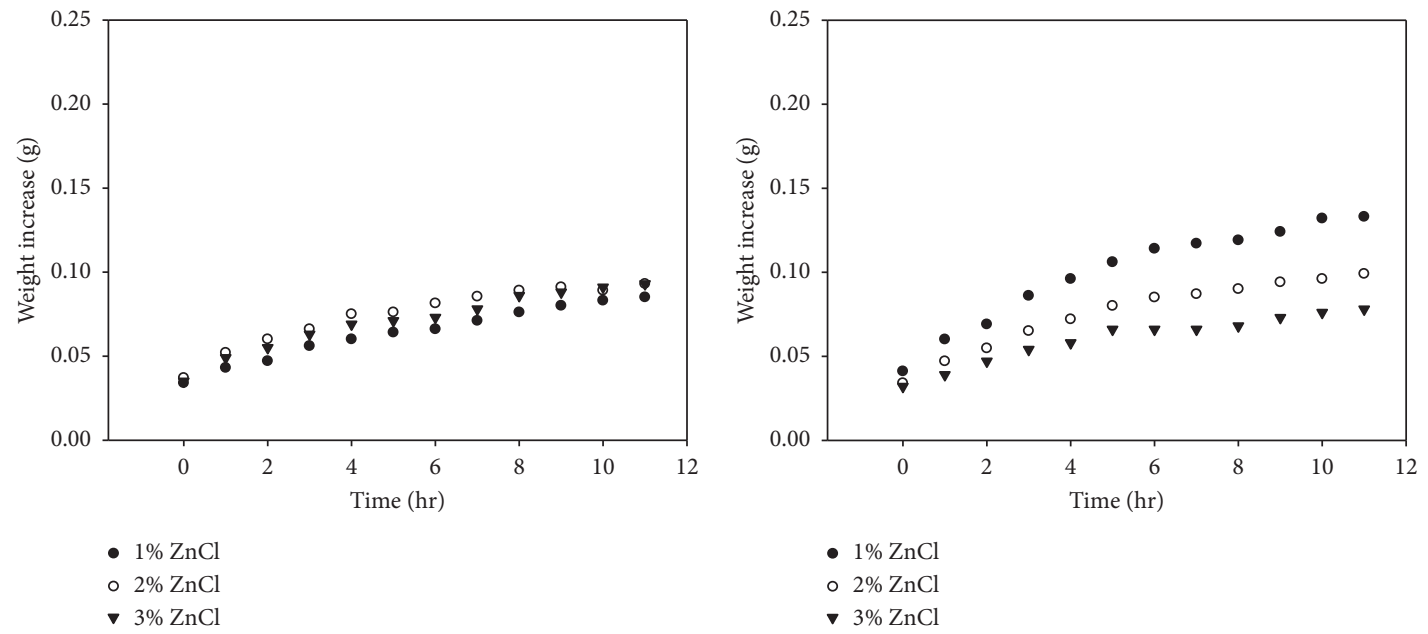

(a)
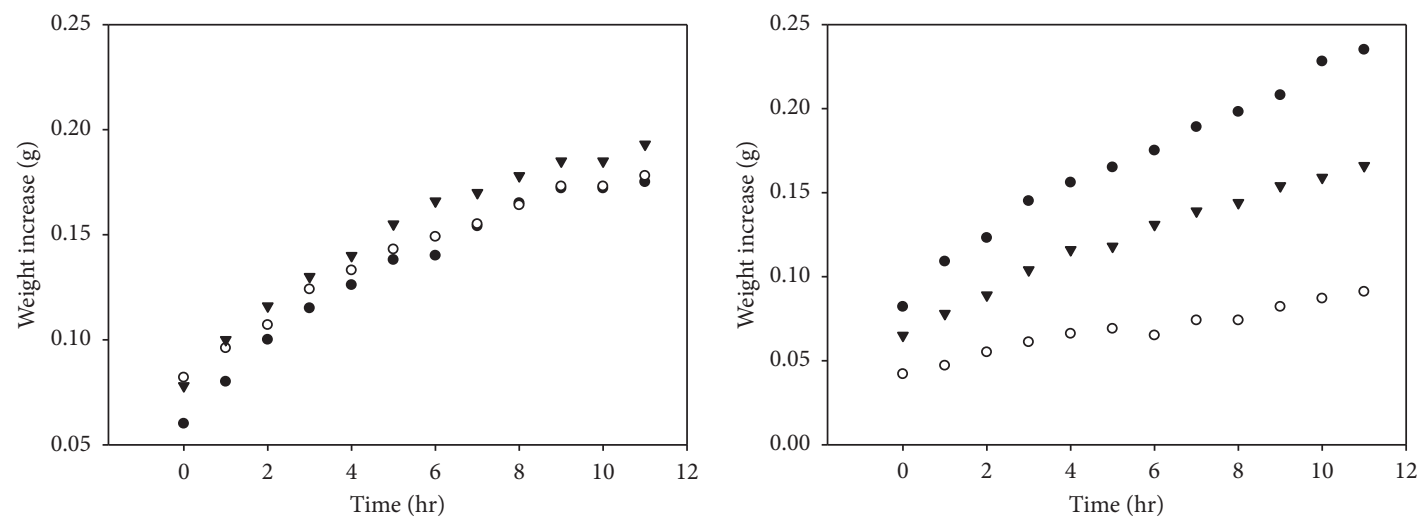

- $1 \% \mathrm{ZnCl}$

- $2 \% \mathrm{ZnCl}$

- $1 \% \mathrm{ZnCl}$

- $2 \% \mathrm{ZnCl}$

> $3 \% \mathrm{ZnCl}$

(c)

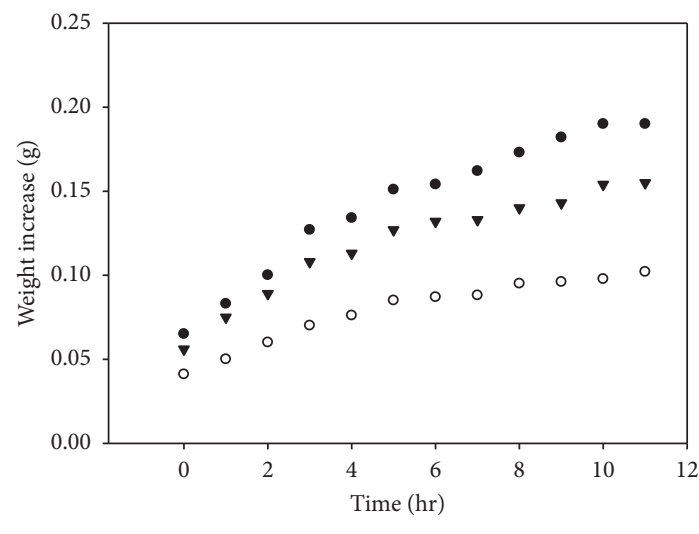

- $1 \% \mathrm{ZnCl}$

- $2 \% \mathrm{ZnCl}$

- $3 \% \mathrm{ZnCl}$

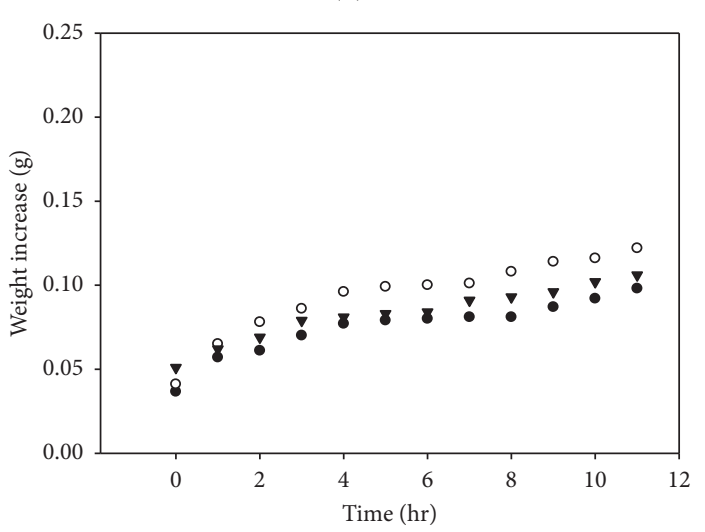

- $1 \% \mathrm{ZnCl}$

- $2 \% \mathrm{ZnCl}$

- $3 \% \mathrm{ZnCl}$

(e)

(f)

FIGURE 9: Water uptake of the epoxydized oils crosslinked with vital gluten or millet flour: weight increase of the epoxydized (a) cottonseed oil/gluten resin, (b) cottonseed oil/millet resin, (c) sesame oil/gluten resin, (d) sesame oil/millet resin, (e) sunflower oil/gluten resin, and (f) sunflower/millet resin. 
IPDT values for the millet-based resin were closer for the $1 \%$ $\mathrm{ZC}$, but the sesame oil resin IPDT vales were scattered for all three ZC levels. Once again, sesame oil exhibited different behaviors compared to the other oils.

3.3. Degradation Kinetics. The degree of conversion is defined as the ratio of the fixed weight loss and the total weight loss. Therefore, the rate of weight loss (degradation) ( $\mathrm{d} a / \mathrm{d} t$ ) is contingent on the temperature and the weight of the sample, as demonstrated by equation (1). The TGA degradation kinetics theory is based on the fact that the activation energy is constant for certain conversions. The log of heating rates as a function of the reciprocal of temperature at each percent conversion presented parallel lines (Figure 7). Figure 8 is a representative example of the three oils and zinc chloride levels. The experimental data are well fitted by the Flynn-Wall-Ozawa method. Figure 8 shows the dependencies of activation energy $\left(E_{\mathrm{a}}\right)$ on the conversion. The sesame-millet resin exhibited the highest $E_{\mathrm{a}}(622 \mathrm{KJ} / \mathrm{mol})$ followed by sunflower-gluten $(496 \mathrm{KJ} / \mathrm{mol})$ and sesamegluten $(454 \mathrm{KJ} / \mathrm{mol})$, whereas the longest range between the $10 \%$ and $70 \%$ conversion was observed for the sesame-millet and sunflower-gluten resins. Sunflower oil resin showed the lowest $E_{\mathrm{a}}$ at $10 \%$ conversion. Figure 8 illustrates the correlation between the $E_{\mathrm{a}}$ and the percent conversion. In the example of vital gluten resin, $E_{\mathrm{a}}$ increased at higher zinc chloride which is consistent with higher crosslinking except for the sesame resin. With respect to millet resin, higher zinc chloride content appeared to reduce the overall activation energy with the exception of the $2 \%$ zinc chloride of the sesame resin (Figure 8 ). $E_{\mathrm{a}}$ of the thermal degradation increases as a function of percent conversion which is typical of polymer degradation [21]. Resin with high stability is reflected as high $E_{\mathrm{a}}$. The increase in $E_{\mathrm{a}}$ is due to the formation of char on the surface which delays heat transfer and consequently slower resin degradation [25]. The average $E_{\mathrm{a}}$ of sesame oil resin was higher than the other oils which indicate that sesame oil promoted thermal stability of the resin. The plot of $E_{\mathrm{a}}$ as a function of percent degradation is frequently used to indicate the degradation mechanism. For example, when the profile consists of one strait line the degradation is considered a one step process, otherwise it is a multistep. In Figure 8, the profiles of all resins point to a multistep degradation, but some of the profiles display two dominant kinetic processes and other resins showed three. $E_{\mathrm{a}}$ at the beginning of degradation was different for almost all samples. This could be attributed to the degree of crosslinking which creates different void volumes as well as volatile components. The reaction mechanism at a higher degree of conversion could be due to multipart reactions during the decomposition. Between 20 and 50\% conversion, $E_{\mathrm{a}}$ appeared to level off and increased after that except for sunflower oil where $E_{\mathrm{a}}$ continues to increase at higher percent degradation (Figure 8).

3.4. Water Uptake. Two approaches to the mechanism of water absorption in epoxy resins have emerged. One is the free volume approach which assumes that water diffuses into the free volume of the resin where bonding between water molecule and epoxy resin network is considered insignificant. The other approach is the interaction concept that proposes that water molecules couple intensely with specific hydrophilic functional groups such as hydroxyl or amine of the resin. The water absorption curves for all composites at the three levels of zinc chloride are illustrated in Figure 9. The results are expressed as weight increase as a function of immersion time. Significant difference between the composites with respect to water uptake was observed especially at a longer immersion time. It is obvious in Figure 9 how zinc chloride affected water uptake because for some composites, the increase in zinc chloride had little effect on the water uptake such as in cottonseed-gluten, sesame-gluten, and sunflower-millet, but for the remaining composites higher water uptake was detected for the lower zinc chloride content. In the most part, the profile of composites with $1 \%$ zinc chloride exhibited the highest water uptake, but the water uptake of the $2 \%$ zinc chloride of the sesame-millet and sunflower-gluten composites was lower than the $3 \%$. This could be attributed to smaller free volume or to the limited hydrophilic groups buried in these composites. In other words, the crosslinking of the $2 \%$ zinc chloride covers more area of the composite than the $3 \%$. Some authors consider highly crosslinked polymers are usually associated with limited chain mobility and thus higher free volume $[26,27]$. It is worth to note that the rates of water absorption were very high at the beginning, where the rate decreased with time. The weight of the resin did not reach equilibrium after 12 hours of the immersion. This fast increase is due to the nature of the components of the composite, mainly the gluten and millet flour. Biomaterials absorb more water than synthetic polymers due to their hydrophilic nature, which may limit their utilization. But, composites with cottonseed-gluten and sunflower-millet were approaching equilibrium after 12 hours. In addition, the water uptake data of the $3 \%$ zinc chloride samples of all three oils were recorded daily after immersion for 8 days. The data showed that, after 5 days, the composites reached moisture equilibrium (data are not shown). Therefore, because water uptake did not reach equilibrium after 12 hours, this may have an adverse effect on the utilization of the composite in the humid environment.

\section{Conclusion}

From the TGA profiles, resins containing higher zinc chloride were more stable. Gluten resin exhibited the overall higher heat stability, but the most heat-resistant resin was the sunflower/millet at 3\% zinc chloride. Sesame oil/millet resin exhibited the highest activation energy followed by sunflower/gluten and sesame/gluten. With some exceptions, lower zinc chloride increased the water uptake of the resins. Generally, the resins did not reach water uptake equilibrium, but composites with cottonseed-gluten and sunflower-millet were approaching equilibrium after 12 hours of immersion. After 5 days of immersion in water, the 3\% zinc chloride resins reached equilibrium. Resins can be ranked as 3\% ZC sunflower-millet $>3 \%$ sunflower-gluten $>3 \%$ cottonseed- 
millet with regard to the remaining degradation residue. This variation in residue content could be attributed to the formation of a layer on the surface of the resin during heating that acted as heat barrier that prevented further degradation. Therefore, the cause of variations between the millet and vital gluten resins is due to the different oil compositions and the effect of zinc chloride level on the crosslinking process.

\section{Data Availability}

The data will be available upon request.

\section{Conflicts of Interest}

The authors declare that they have no conflicts of interest.

\section{Acknowledgments}

The authors extend their appreciation to the Deanship of Scientific Research at King Saud University for funding this work through the research group no RGP-114.

\section{References}

[1] C. Zheng, M. Liu, Y. Yin et al., "Kinetics and thermal properties of epoxy resins containing the ionic liquid $\left[\mathrm{C}_{6} \mathrm{mim}\right] \mathrm{FeCl}_{4}$," RSC Advances, vol. 6, no. 14, pp. 11407-11411, 2016.

[2] C. E. Estridge, "The effects of competitive primary and secondary amine reactivity on the structural evolution and properties of an epoxy thermoset resin during cure: a molecular dynamics study," Polymer, vol. 141, pp. 12-20, 2018.

[3] P. Mohan, "A critical review: the modification, properties, and applications of epoxy resins," Polymer-Plastics Technology and Engineering, vol. 52, no. 2, pp. 107-125, 2013.

[4] S. V. Levchik and E. D. Weil, "Thermal decomposition, combustion and flame-retardancy of epoxy resins-a review of the recent literature," Polymer International, vol. 53, no. 12, pp. 1901-1929, 2004.

[5] P. Tranchard, Modelling the Behaviour of a Carbon/Epoxy Composite Submitted to Fire, Unversity of Lille, Lille, France, 2015.

[6] A. Afaghi Khatibi, V. Chevali, S. Feih, and A. P. Mouritz, "Probability analysis of the fire structural resistance of aluminium plate," Fire Safety Journal, vol. 83, pp. 15-24, 2016.

[7] B. Mortaigne and N. Régnier, "Study of epoxy and epoxycyanate networks thermal degradation to predict materials lifetime in use conditions," Journal of Applied Polymer Science, vol. 77, no. 14, pp. 3142-3153, 2000.

[8] J. Opfermann and E. Kaisersberger, "An advantageous variant of the ozawa-flynn-wall analysis," Thermochimica Acta, vol. 203, pp. 167-175, 1992.

[9] T. Ozawa, "A new method of analyzing thermogravimetric data," Bulletin of the Chemical Society of Japan, vol. 38, no. 11, pp. 1881-1886, 1965.

[10] H. L. Friedman, "Kinetics of thermal degradation of charforming plastics from thermogravimetry: application to a phenolic plastic," Journal of Polymer Science Part C: Polymer Symposia, vol. 6, no. 1, pp. 183-195, 1964.

[11] M. E. Brown, M. Maciejewski, S. Vyazovkin et al., "Computational aspects of kinetic analysis: part a: the ICTAC kinetics project-data, methods and results," Thermochimica Acta, vol. 355, no. 1-2, pp. 125-143, 2000.
[12] P. Tranchard, F. Samyn, S. Duquesne, B. Estèbe, and S. Bourbigot, "Modelling behaviour of a carbon epoxy composite exposed to fire: part I-characterisation of thermophysical properties," Materials, vol. 10, no. 5, p. 494, 2017.

[13] V. Mamleev, S. Bourbigot, M. L. Bras, and J. Lefebvre, "Three model-free methods for calculation of activation energy in TG," Journal of Thermal Analysis and Calorimetry, vol. 78, no. 3, pp. 1009-1027, 2004.

[14] ASTM_E698-18, Standard Test Method for Arrhenius Kinetic Constants for Thermally Unstable Materials Using Differential Scanning Calorimetry and the Flynn/Wall/Ozawa Method, ASTM International, West Conshohocken, PA, USA, 2018.

[15] E. Moukhina, "Determination of kinetic mechanisms for reactions measured with thermoanalytical instruments," Journal of Thermal Analysis and Calorimetry, vol. 109, no. 3, pp. 1203-1214, 2012.

[16] O. Becker, R. J. Varley, and G. P. Simon, "Thermal stability and water uptake of high performance epoxy layered silicate nanocomposites," European Polymer Journal, vol. 40, no. 1, pp. 187-195, 2004.

[17] W. Xie, Z. Gao, W.-P. Pan, D. Hunter, A. Singh, and R. Vaia, "Thermal degradation chemistry of alkyl quaternary ammonium montmorillonite," Chemistry of Materials, vol. 13, no. 9, pp. 2979-2990, 2001.

[18] C. L. Soles, F. T. Chang, D. W. Gidley, and A. F. Yee, "Contributions of the nanovoid structure to the kinetics of moisture transport in epoxy resins," Journal of Polymer Science Part B: Polymer Physics, vol. 38, no. 5, pp. 776-791, 2000.

[19] A. Tscharkhtchi, P. Y. Bronnec, and J. Verdu, "Water absorption characteristics of butane diol-3,5-diethyl-2,4-diaminotoluene networks," Polymer, vol. 41, no. 15, pp. 5777-5785, 2000.

[20] R. E. Harry-O’kuru, A. Mohamed, S. H. Gordon, and J. Xu, "Syntheses of novel protein products (milkglyde, saliglyde, and soyglyde) from vegetable epoxy oils and gliadin," Journal of Agricultural and Food Chemistry, vol. 60, no. 7, pp. 16881694, 2012.

[21] S. Vyazovkin and N. Sbirrazzuoli, "Isoconversional kinetic analysis of thermally stimulated processes in polymers," Macromolecular Rapid Communications, vol. 27, no. 18, pp. 1515-1532, 2006.

[22] Y. Qian, P. Wei, P. Jiang, X. Zhao, and H. Yu, "Synthesis of a novel hybrid synergistic flame retardant and its application in PP/IFR," Polymer Degradation and Stability, vol. 96, no. 6, pp. 1134-1140, 2011.

[23] G. Y. You, Z. Q. Cheng, H. Peng, and H. W. He, "Synthesis and performance of a novel nitrogen-containing cyclic phosphate for intumescent flame retardant and its application in epoxy resin," Journal of Applied Polymer Science, vol. 132, no. 16, 2015.

[24] X. Xiong, L. Zhou, R. Ren, S. Liu, and P. Chen, "The thermal decomposition behavior and kinetics of epoxy resins cured with a novel phthalide-containing aromatic diamine," Polymer Testing, vol. 68, pp. 46-52, 2018.

[25] C.-L. Chiang, R.-C. Chang, and Y.-C. Chiu, "Thermal stability and degradation kinetics of novel organic/inorganic epoxy hybrid containing nitrogen/silicon/phosphorus by sol-gel method," Thermochimica Acta, vol. 453, no. 2, pp. 97-104, 2007.

[26] A. Toscano, G. Pitarresi, M. Scafidi, M. Di Filippo, G. Spadaro, and S. Alessi, "Water diffusion and swelling stresses in highly crosslinked epoxy matrices," Polymer Degradation and Stability, vol. 133, pp. 255-263, 2016. 
[27] S. Alessi, E. Caponetti, O. Güven, M. Akbulut, G. adaro, and A. Spinella, "Study of the curing process of DGEBA epoxy resin through structural investigation," Macromolecular Chemistry and Physics, vol. 216, no. 5, pp. 538-546, 2015. 

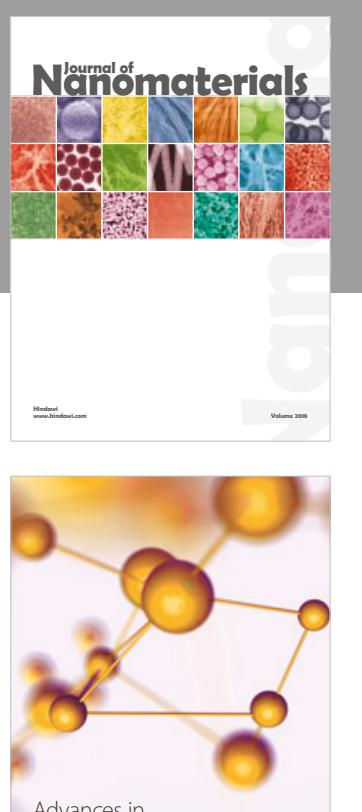

Physical Chemistry
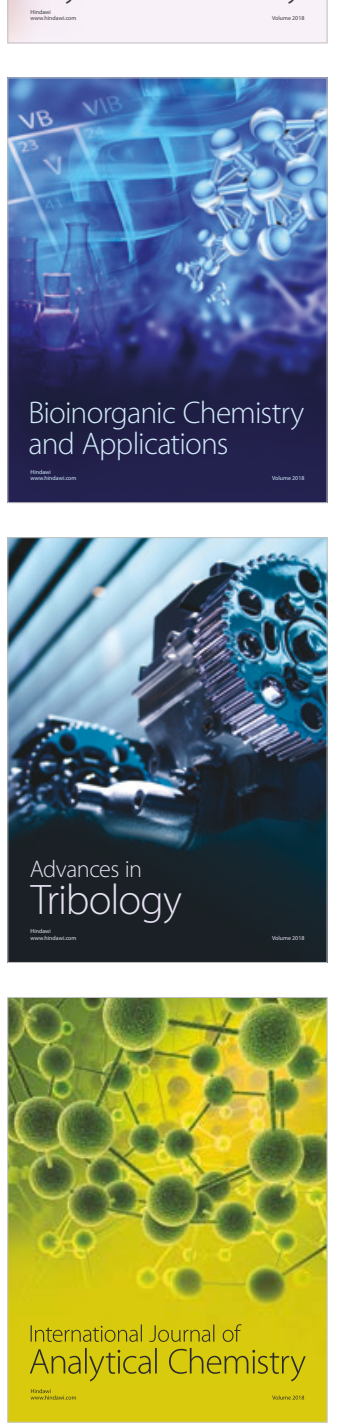

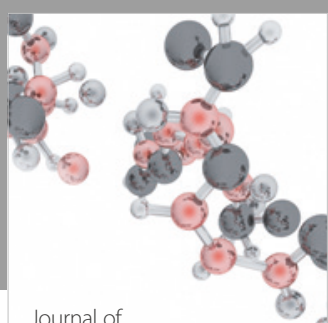

Analytical Methods

in Chemistry

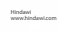

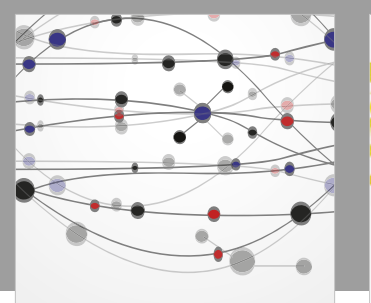

The Scientific World Journal

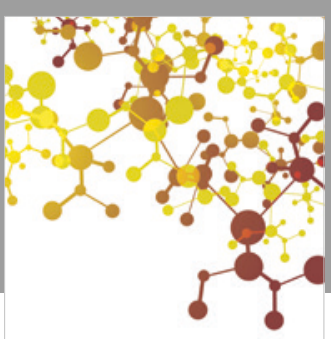

Journal of

Applied Chemistry
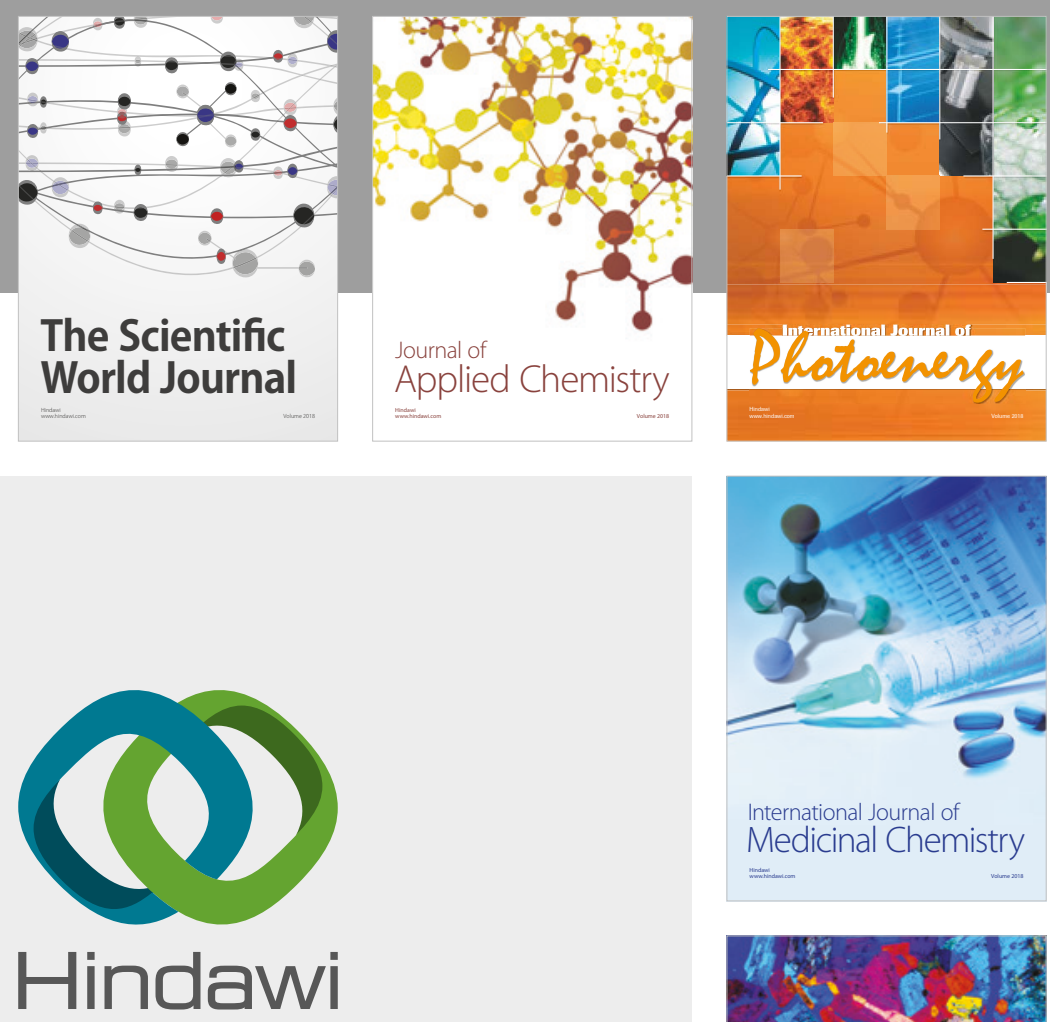

Submit your manuscripts at

www.hindawi.com
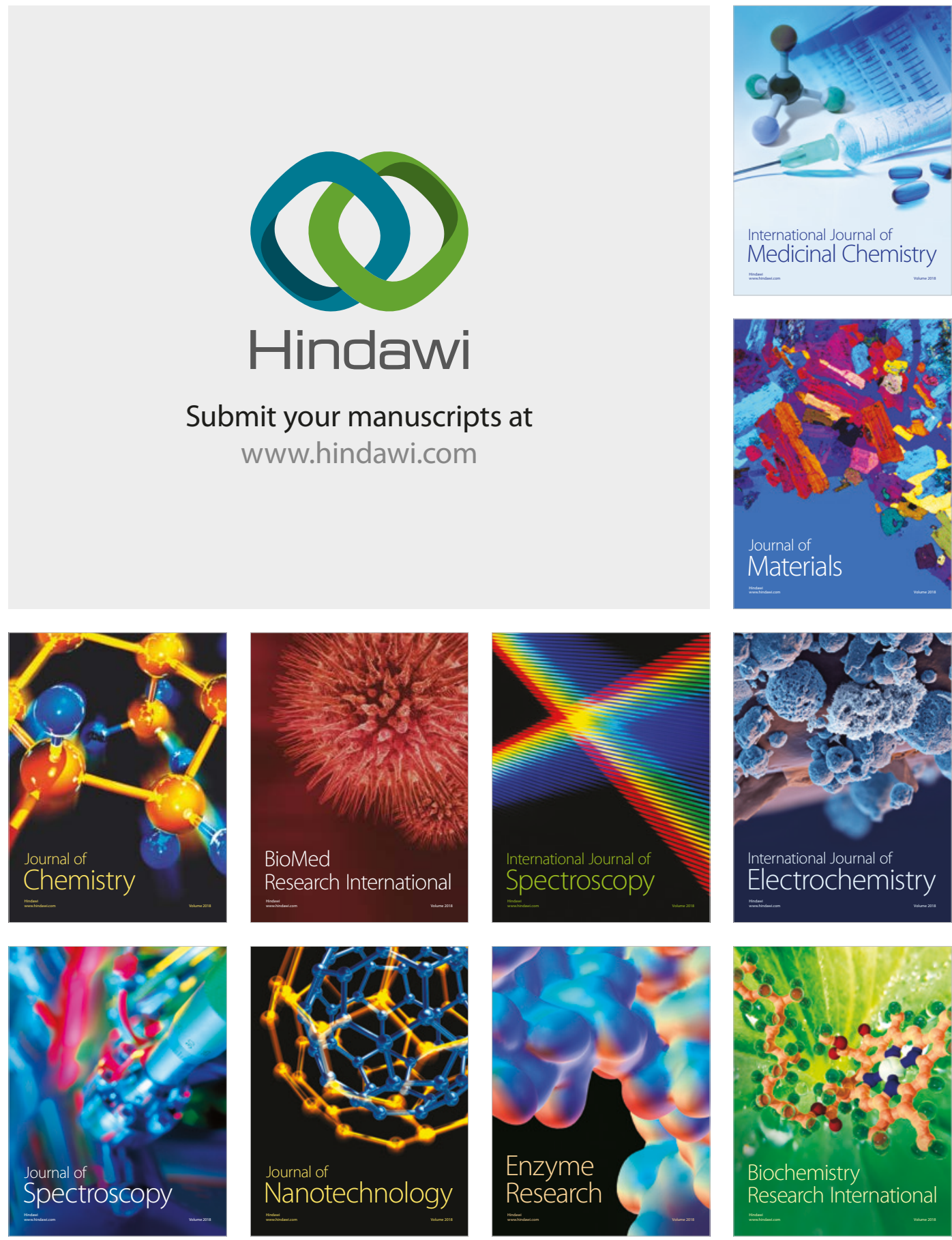
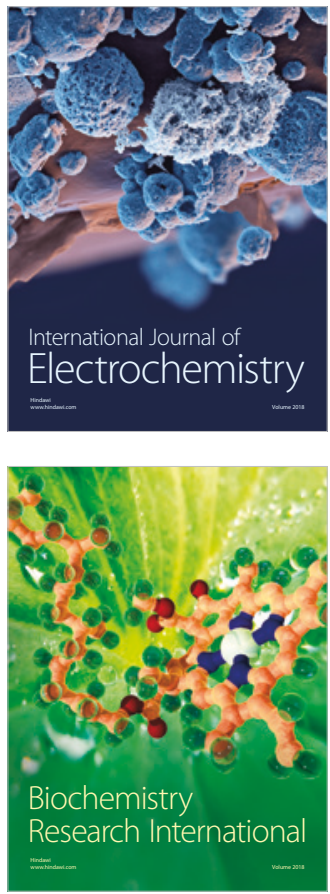